University of Nebraska - Lincoln

DigitalCommons@University of Nebraska - Lincoln

\title{
Evidence of Resistance to Cry34/35Ab1 Corn by Western Corn Rootworm (Coleoptera: Chrysomelidae): Root Injury in the Field and Larval Survival in Plant-Based Bioassays
}

\author{
Aaron J. Gassmann \\ lowa State University, aaronjg@iastate.edu \\ Ram B. Shrestha \\ lowa State University, shrestrb@iastate.edu \\ Siva R. K. Jakka \\ lowa State University, sjakk@valent.com \\ Mike W. Dunbar \\ lowa State University, dunbar@iastate.edu \\ Eric H. Clifton \\ lowa State University, eclifton@iastate.edu \\ See next page for additional authors \\ Follow this and additional works at: https://digitalcommons.unl.edu/usdaarsfacpub
}

Gassmann, Aaron J.; Shrestha, Ram B.; Jakka, Siva R. K.; Dunbar, Mike W.; Clifton, Eric H.; Paolino, Aubrey R.; Ingber, David A.; French, B. Wade; Masloski, Kenneth E.; Dounda, John W.; and Clair, Coy R. St., "Evidence of Resistance to Cry34/35Ab1 Corn by Western Corn Rootworm (Coleoptera: Chrysomelidae): Root Injury in the Field and Larval Survival in Plant-Based Bioassays" (2016). Publications from USDA-ARS / UNL Faculty. 1591.

https://digitalcommons.unl.edu/usdaarsfacpub/1591

This Article is brought to you for free and open access by the U.S. Department of Agriculture: Agricultural Research Service, Lincoln, Nebraska at DigitalCommons@University of Nebraska - Lincoln. It has been accepted for inclusion in Publications from USDA-ARS / UNL Faculty by an authorized administrator of DigitalCommons@University of Nebraska - Lincoln. 


\section{Authors}

Aaron J. Gassmann, Ram B. Shrestha, Siva R. K. Jakka, Mike W. Dunbar, Eric H. Clifton, Aubrey R. Paolino, David A. Ingber, B. Wade French, Kenneth E. Masloski, John W. Dounda, and Coy R. St. Clair 


\title{
Evidence of Resistance to Cry34/35Ab1 Corn by Western Corn Rootworm (Coleoptera: Chrysomelidae): Root Injury in the Field and Larval Survival in Plant-Based Bioassays
}

\author{
Aaron J. Gassmann, ${ }^{1,2}$ Ram B. Shrestha, ${ }^{1}$ Siva R. K. Jakka, ${ }^{1,3}$ Mike W. Dunbar, ${ }^{1}$ \\ Eric H. Clifton, ${ }^{1}$ Aubrey R. Paolino, ${ }^{1}$ David A. Ingber, ${ }^{1,4}$ B. Wade French, ${ }^{5}$ \\ Kenneth E. Masloski, ${ }^{1}$ John W. Dounda, ${ }^{1}$ and Coy R. St. Clair ${ }^{1}$ \\ 1Department of Entomology, lowa State University, Ames, IA 50011 (aaronjg@iastate.edu; shrestrb@iastate.edu; \\ dunbar@iastate.edu; eclifton@iastate.edu; apaolino@iastate.edu; masloski@iastate.edu; jdoudna@iastate.edu; cstclair@iasta- \\ te.edu), ${ }^{2}$ Corresponding author, e-mail: aaronjg@iastate.edu, ${ }^{3}$ Current address: Valent U.S.A. Company, 3800 Old Leland Rd., \\ Leland, MS 38756 (sjakk@valent.com), ${ }^{4}$ Current address: Department of Entomology and Wildlife Ecology, University of Delaware, \\ Newark, DE 19716 (davidngbr@gmail.com), and ${ }^{5}$ USDA ARS North Central Agricultural Research Laboratory, Brookings, SD \\ (wade.french@ars.usda.gov)
}

Received 12 January 2016; Accepted 3 May 2016

\begin{abstract}
Western corn rootworm, Diabrotica virgifera virgifera LeConte (Coleoptera: Chrysomelidae), is a serious pest of corn in the United States, and recent management of western corn rootworm has included planting of Bt corn. Beginning in 2009, western corn rootworm populations with resistance to Cry3Bb1 corn and mCry3A corn were found in lowa and elsewhere. To date, western corn rootworm populations have remained susceptible to corn producing Bt toxin Cry34/35Ab1. In this study, we used single-plant bioassays to test field populations of western corn rootworm for resistance to Cry34/35Ab1 corn, Cry3Bb1 corn, and mCry3A corn. Bioassays included nine rootworm populations collected from fields where severe injury to Bt corn had been observed and six control populations that had never been exposed to Bt corn. We found incomplete resistance to Cry34/35Ab1 corn among field populations collected from fields where severe injury to corn producing Cry34/35Ab1, either singly or as a pyramid, had been observed. Additionally, resistance to Cry3Bb1 corn and mCry3A corn was found among the majority of populations tested. These first cases of resistance to Cry34/35Ab1 corn, and the presence of resistance to multiple Bt toxins by western corn rootworm, highlight the potential vulnerability of Bt corn to the evolution of resistance by western corn rootworm. The use of more diversified management practices, in addition to insect resistance management, likely will be essential to sustain the viability of Bt corn for management of western corn rootworm.
\end{abstract}

Key words: bioassay, Diabrotica virgifera virgifera, insect resistance management, integrated pest management, refuge strategy

The western corn rootworm, Diabrotica virgifera virgifera LeConte (Coleoptera: Chrysomelidae), is among the most serious pests of corn in the United States and imposes annual economic losses to farmers in excess of $\$ 1$ billion US, as a result of management costs and lost yield (Gray et al. 2009, Dun et al. 2010). Larvae from this univoltine species feed on corn roots while adults feed primarily on corn silk, pollen, and developing ears (Meinke et al. 2009). With the exception of rotation-resistant western corn rootworm, eggs are deposited by females in the soil of cornfields, and the egg is the overwintering stage for this insect (Spencer et al. 2009). The vast majority of yield loss from western corn rootworm arises from feeding of larval rootworm on corn roots, although adult feeding on developing corn ears also may reduce yield (Gray et al. 2009). On average, yield is reduced by $15-17 \%$ for every node of roots lost to larval feeding by western corn rootworm (Dun et al. 2010, Tinsley et al. 2013). Management of western corn rootworm has included use of soil-applied insecticides to reduce larval feeding on corn roots, rotation of fields to crops other than corn to kill larvae, and aerial application of insecticides to reduce egg laying by females, and in some cases, to reduce adult feeding on corn ears (Levine and Oloumi-Sadeghi 1991). The most recent innovation for management of western corn rootworm is genetically modified corn that produces insecticidal toxins derived from the bacterium Bacillus thuringiensis (Bt) (EPA 2016b).

Bt corn targets rootworm larvae, and feeding on Bt corn by western corn rootworm larvae imposes larval mortality and reduces feeding injury to corn roots (Petzold-Maxwell et al. 2013a, 2013b; Keweshan et al. 2015). Bt corn was first registered for management of western corn rootworm in 2003, and this type of Bt corn 
produced Bt toxin Cry3Bb1 (EPA 2010). Additional Bt toxins for the management of western corn rootworm have included Cry34/ $35 \mathrm{Ab} 1$ corn and mCry3 A corn, which were registered in 2005 and 2006, respectively (EPA 2005, 2006). All of these Bt toxins were initially released singly. More recently, Bt toxins have been released as pyramids, including Cry34/35Ab1 with Cry3Bb1 in 2009 and Cry34/35Ab1 with mCry3A in 2011 (EPA 2009, 2011a, 2012).

Challenges surrounding management of western corn rootworm have been compounded by the evolution of resistance to multiple management strategies, including Bt corn, crop rotation, and conventional insecticides. In the $1980 \mathrm{~s}$, rotation-resistant western corn rootworm were identified in eastern Illinois, and this variant of the western corn rootworm was found to circumvent management with crop rotation by ovipositing outside of cornfields, often in soybean fields, which were then rotated to corn the following year (Spencer et al. 2005, 2014). Additionally, during the 1990s, resistance by adults to methyl parathion and carbaryl was identified in Nebraska, and greatly limited the ability of farmers to manage rootworm populations by killing adult rootworm (Meinke et al. 1998). Beginning in 2009 , fields in Iowa were identified with severe feeding injury to Cry3Bb1 corn, and subsequent bioassays found that this injury was associated with resistance to Cry3Bb1 corn (Gassmann et al. 2011). Fields with Cry3Bb1-resistant western corn rootworm also were collected in Iowa during 2010 and 2011, and cross-resistance was identified between Cry3Bb1 corn and mCry3A corn (Gassmann et al. 2012, 2014). Similarly, resistance to Cry3Bb1 corn and crossresistance between Cry3Bb1 and mCry3A was identified for western corn rootworm populations from Nebraska (Wangila et al. 2015), and resistance to Cry3Bb1 corn has been confirmed in Illinois (Schrader et al. 2016). To date, however, western corn rootworm populations have not developed resistance to Cry34/35Ab1 corn (Gassmann et al. 2011, 2012, 2014; Wangila et al. 2015).

Management of resistance to Bt corn by western corn rootworm relied initially on the refuge strategy, with non-Bt corn grown in conjunction with Bt corn to promote the survival of Bt-susceptible pests. The refuge strategy is expected to be most effective at delaying resistance when a Bt crop produces a high dose of Bt toxin, because highdose Bt crops will kill both susceptible and heterozygous individuals and render resistance a functionally recessive trait (Gould 1998). However, none of the currently commercialized Bt events targeting western corn rootworm are considered high dose (Gassmann 2012, Andow et al. 2016). More recently, resistance management for western corn rootworm also has incorporated pyramiding of multiple Bt toxins. Although pyramids can delay resistance when Bt traits do not produce a high dose of toxin, resistance-allele frequency will affect how quickly pest populations adapt to a pyramid, with more rapid resistance evolution expected at higher initial frequencies for resistance alleles (Roush 1998). Cases of resistance to Cry3Bb1 and mCry3A increase the vulnerability of some pyramids to the rapid evolution of resistance, and all current rootworm pyramids contain either mCry3A or Cry3Bb1 (Cullen et al. 2013). As a result, there is the potential for western corn rootworm to adapt to Cry34/35Ab1 corn, and past laboratory studies have found that resistance to Cry34/35Ab1 corn can evolve following four generations of on-plant selection (Deitloff et al. 2015).

In the present study, we conducted plant-based bioassays to measure susceptibility of western corn rootworm populations to three types of $\mathrm{Bt}$ corn: Cry34/35Ab1 corn, Cry3Bb1 corn, and mCry3A corn. Western corn rootworm were collected from fields where injury to various types of Bt corn occurred, including Cry34/35Ab1 corn, Cry3Bb1 corn, and corn that was pyramided with Cry34/35Ab1 and either mCry3A or Cry3Bb1. The goal of this study was to determine if injury in the field to corn producing Bt toxin Cry34/35Ab1 was associated with resistance to Cry34/35Ab1, and the extent to which field populations were resistant to multiple Bt toxins. The results of this study will be useful for understanding resistance to Bt corn by western corn rootworm, and improving approaches for managing Bt resistance by this pest.

\section{Materials and Methods}

Cornfields were visited during the summer of 2013 in response to complaints by farmers and crop consultants of rootworm feeding injury to Bt corn (Fig. 1). Field visits followed established protocols described in Gassmann et al. (2014). At each field, the location was recorded using a global positioning system (GPS; Legend HCX, Garmin, Olathe, KS). The relative proportion of western corn rootworm and northern corn rootworm in each field was estimated based on visual observation of adult rootworm on corn plants. In all cases, the vast majority (i.e., $\geq 95 \%$ ) of adult corn rootworm in each field were western corn rootworm. Adult western corn rootworm $(N=81-398 ;$ mean $=217)$ were collected from each field to obtain eggs for subsequent bioassays. Corn roots $(N=11-24)$ were sampled from each field along two to four transects. Transects were at least $15 \mathrm{~m}$ from the edge of the field and separated from each other by at least $15 \mathrm{~m}$. Roots $(N=5-7)$ were sampled every $2 \mathrm{~m}$ along each transect. The presence or absence of rootworm active Bt toxin in each corn plant was tested with ELISA using a kit (Envirologix, Portland, ME), and for the majority of fields, a mixture of $\mathrm{Bt}$ and non-Bt corn plants were sampled (Table 1). Soil was washed from roots, and roots were rated for rootworm feeding injury following the 0 to 3 node injury scale of Oleson et al. (2005).

Adult western corn rootworm from each field were held in separate cages ( 18 by 18 by $18 \mathrm{~cm}$; L by W by H; Megaview Science, Taiwan) housed in an incubator $\left(25^{\circ} \mathrm{C}\right.$ and a photoperiod of $16: 8$ [L:D] h). Insects were provided with a complete adult diet (western corn rootworm adult diet, product \# F9768B-M, Bio-Serv, Frenchtown, NJ), corn leaf tissue, a $1.5 \%$ agar solid as a source of water, and sieved soil $(<180 \mu \mathrm{m})$ held in a Petri dish (diameter $=10 \mathrm{~cm}$ ) as an oviposition substrate. Eggs collected from each population were placed in a cold room at $6^{\circ} \mathrm{C}$ for at least 5 mo to break diapause, after which time eggs were removed from the cold room and placed in an incubator $\left(25^{\circ} \mathrm{C}\right.$ and a photoperiod of $16: 8$ [L:D] h) where they hatched two weeks later.

Newly hatched neonates were used in plant-based bioassays following Gassmann et al. (2014). Briefly, plants were grown singly in

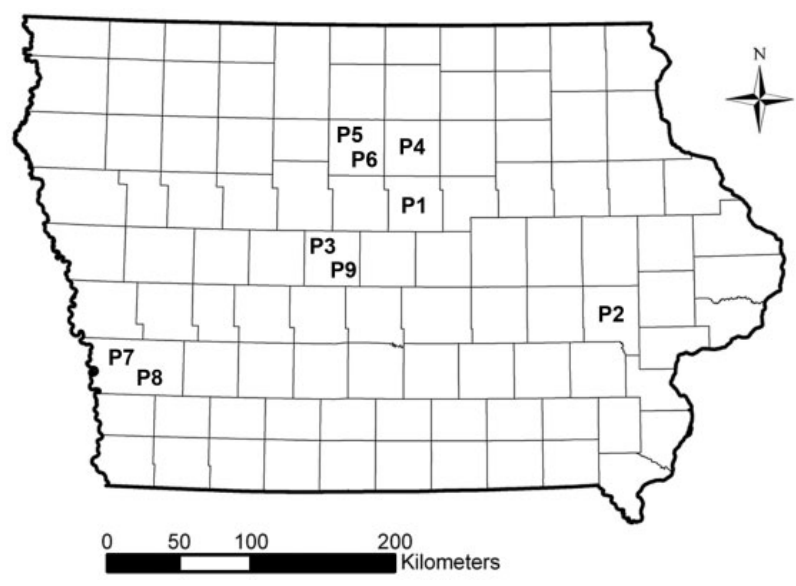

Fig. 1. Location of field visited in 2013. Codes for each field (e.g., P1) correspond to data presented in Table 1. Location of sites is accurate to the level of an individual county. 
Table 1. Date sampled, root injury, and field history of populations used in bioassays

\begin{tabular}{|c|c|c|c|c|c|c|c|c|c|c|}
\hline \multirow[t]{2}{*}{ Site } & \multirow[t]{2}{*}{ Bt $\operatorname{corn}^{a, b}$} & \multirow[t]{2}{*}{ Date sampled } & \multirow[t]{2}{*}{ Root injury ${ }^{c} \mathrm{Bt}$} & \multirow[t]{2}{*}{ Root injury $^{c}$ non-Bt } & \multicolumn{6}{|c|}{ Field history $b, d$} \\
\hline & & & & & $1^{e}$ & 2 & 3 & 4 & 5 & 6 \\
\hline P1 & 4 & 10 Sept. & $2.34 \pm 0.68(12)$ & unknown & 2 & 0 & 0 & 1 & 0 & 0 \\
\hline P2 & 4 & 12 Aug. & $2.04 \pm 0.64(17)$ & $1.77 \pm 0.25$ & 3 & 1 & 0 & 1 & 0 & 0 \\
\hline P3 & 5 & 10 Sept. & $1.61+0.93(20)$ & $1.80 \pm 1.30(4)$ & 7 & 3 to $4^{f}$ & 0 & 1 to $2^{f}$ & 1 & 0 \\
\hline P4 & 6 & 12 Sept. & $1.11+0.51(17)$ & $1.14 \pm \mathrm{NA}(1)$ & 11 & 1 to $2^{f}$ & 0 & 4 to $6^{f}$ & 0 & 1 \\
\hline P5 & 5 & 06 Aug. & $0.96+0.16(14)$ & unknown & 8 & 1 & 1 & 2 & 1 & 0 \\
\hline P6 & 5 & 06 Aug. & $0.70+0.90(12)$ & $1.58+0.80(6)$ & 2 & 0 & 0 & 0 & 1 & 0 \\
\hline P7 & 2 & 03 Sept. & $2.76+0.26(10)$ & $2.00+\mathrm{NA}(1)$ & 2 to $4^{f}$ & 2 to $3^{f}$ & 0 & 0 & 0 & 0 \\
\hline P8 & 2 & 03 Sept. & $2.41+0.41(9)$ & $2.03+0.95(3)$ & 2 to $4^{f}$ & 2 to $3^{f}$ & 0 & 0 & 0 & 0 \\
\hline P9 & 2 & 01 Aug. & $2.40+0.50(12)$ & unknown & 10 & 7 & 0 & 1 & 0 & 0 \\
\hline
\end{tabular}

${ }^{a}$ Type of Bt corn evaluated for root injury.

${ }^{b}$ Types of Bt corn were: $2=$ Cry3Bb1, $3=$ mCry3A, $4=$ Cry34/35Ab1, $5=$ Cry3Bb1 + Cry34/35Ab1, 6= mCry3A + Cry34/35Ab1.

${ }^{c}$ Mean \pm SD for root injury on a 0 to 3 node injury scale (Oleson et al. 2005). Numbers in parentheses are sample sizes.

${ }^{d}$ Number of years corn was planted (column 1) and number of years each type of Bt corn was planted (column 2 to 6 ). Data on Bt corn exclude the first year corn was grown in a field because western corn rootworm larvae were not present to experience selection.

${ }^{e}$ Number of years corn was planted since either 2003 (the year Bt corn was commercialized for western corn rootworm) or the field was last planted to a crop other than corn, whichever is smaller.

${ }^{f}$ There was uncertainty regarding field history and this is reflected in the range of values.

1-liter containers in the greenhouse to the V5 to V6 stage (i.e., five to six leaf stage (Abendroth et al. 2011)). None of the corn seed used in this study contained a pesticidal seed treatment, but all seed was soaked in a $10 \%$ bleach solution for $1 \mathrm{~h}$ and then rinsed thoroughly 10 times prior to planting. This was done to remove any traces of pesticide that may have been present on seeds from processing and handling prior to arrival at Iowa State University. Plants at the V5 to V6 stage (ca. 4 wk after planting) were brought to the laboratory and used in plant-based bioassays. Plants were trimmed to a height of $20 \mathrm{~cm}$ and all but two leaves removed, which were trimmed to a length of $8 \mathrm{~cm}$. This was done so plants would fit within an environmental chamber. Each plant received 12 neonate larvae $(<1 \mathrm{~d}$ old $)$, which were placed at the base of the plant on roots that were exposed by moving a small amount of soil. Once larvae were placed on plants, roots were gently covered with soil again. A barrier was placed around the top of each container (Tree Tanglefoot, The Tanglefoot Company, Grand Rapids, MI) to ensure that no larvae escaped from bioassay containers. Bioassay containers with larvae and corn plants then were placed in an incubator $\left(24^{\circ} \mathrm{C}\right.$, $60 \% \mathrm{RH}$, and a photoperiod of 16:8 [L:D] h) for $17 \mathrm{~d}$.

After $17 \mathrm{~d}$, plants were removed from the incubator, the aboveground vegetative tissue was removed, and roots, soil, and larvae were transferred to a Berlese funnel for $4 \mathrm{~d}$ to extract larvae from the soil. Larvae from each plant were collected in a 15 -ml glass vial containing $85 \%$ ethanol. The proportion of larvae surviving on each plant was calculated as the number of larvae recovered divided by the number of neonates placed on a plant. Larval head capsule width was measured using a microscope (Leica MZ6, Wetzlar, Germany) with a digital camera (Moticam 2500, Meyer Instruments, Houston, TX) and image analysis software (Motic Images Plus 2.0 ML, Motic Images Inc., British Columbia, Canada), and larval instar was determined based on head capsule width following Hammack et al. (2003). For each plant from which larvae were recovered, the proportion of larvae in each instar was calculated as the number of larvae in a specific instar (e.g., first) divided by the total number of larvae recovered.

One population was tested per week and bioassays alternated between field populations and control populations. Control populations consisted of diapausing strains of western corn rootworm that were brought into laboratory culture before 2003, the year that $\mathrm{Bt}$ corn was commercialized for management of western corn rootworm (EPA 2016b). Control populations were provided as eggs in diapause from USDA Agricultural Research Service's North Central Agricultural Research Laboratory (Brookings, SD). For control populations, the location and year of collection were: Phelps Co., NE, 1995; Potter Co., SD, 1995; York Co., NE, 1996; Butler Co., NE, 1999; Centre Co., PA, 2000; Finney Co., KS, 2000.

In total, nine field populations were tested in bioassays and these fields were distributed among each of four population classes: 1 ) fields with $>2$ nodes of injury to Cry34/35Ab1 corn (P1 and P2 in Table 1), 2) fields with $>1$ node of root injury to corn pyramided with Cry34/35Ab1 and either mCry3A or Cry3Bb1 (fields P3 and P4 in Table 1), 3) fields with $>0.5$ nodes but $<1.0$ node of injury to corn pyramided with Cry34/35Ab1 and Cry3Bb1 (fields P5 and P6 in Table 1), and 4) fields with $>2$ nodes of injury to Cry3Bb1 corn (fields P7, P8, and P9 in Table 1).

Populations were grouped into these four classes to test specific hypothesis about the type of Bt resistance that may be contributing to injury in the field. The specific hypotheses tested were: H1) for fields with $>2$ nodes of injury to Cry34/35Ab1 corn, western corn rootworm populations with resistance to Cry34/35Ab1 would be present, H2) for fields with $>1$ node of root injury to corn pyramided with Cry34/35Ab1 and either mCry3A or Cry3Bb1, western corn rootworm populations with resistance to Cry34/35Ab1, mCry3A, and Cry3Bb1 would be present, H3) for fields with $>0.5$ nodes but $<1.0$ node of injury to corn pyramided with Cry34/ $35 \mathrm{Ab} 1$ and Cry3Bb1, western corn rootworm populations with resistance to Cry34/35Ab1, mCry3A, and Cry3Bb1 would be present, but this resistance would be less than fields where greater than a node of injury was observed to pyramided corn, H4) for fields with $>2$ nodes of injury to Cry3Bb1 corn, western corn rootworm populations with resistance to Cry3Bb1 and mCry3A corn would be present. In general, we hypothesized that resistance to a specific $\mathrm{Bt}$ toxin would be present in a western corn rootworm population when corn with that Bt toxin suffered high levels of injury in the field (e.g., severe feeding injury to Cry3Bb1 corn would be associated with $\mathrm{Cry} 3 \mathrm{Bb} 1$ resistance). In cases where resistance to Cry3Bb1 was present, we hypothesized that $\mathrm{mCry} 3 \mathrm{~A}$ resistance also would be present because of previous research indicating cross-resistance between these Bt toxins (Gassmann et al. 2014, Wangila et al. 2015). 
Each of these 15 populations (six control populations and nine field populations) was tested against six corn hybrids: 1) Cry34/35Ab1 corn (event DAS-59122-7), 2) non-Bt near isoline to Cry34/35Ab1 corn, 3) Cry3Bb1 corn (event MON 88017), 4) non-Bt near isoline to Cry3Bb1 corn, 5) mCry3A corn (event MIR 604), and 6) non-Bt near isoline to mCry $3 \mathrm{~A}$ corn. The same six corn hybrids were used in bioassays to evaluate each of the 15 populations. For each combination of population by hybrid, between 5 and 10 single-plant bioassays were conducted (mean$=8.77 ; \mathrm{SD}=1.25$ ) for a total of 789 single-plant bioassays for the entire experiment $(15$ populations $\times 6$ hybrids $\times 8.77$ replications). Bioassays were conducted between April and September of 2014.

\section{Data Analysis}

Data on proportion survival in bioassays were analyzed separately by hybrid with a mixed-model analysis of variance ANOVA (PROC MIXED) in SAS (SAS 2013). Data were analyzed separately by hybrid to ensure the data met the ANOVA assumption of homogeneity of variance. Data were transformed by the arcsine of the square root to ensure normality of the residuals. The fixed factor in each ANOVA was population class, which consisted of: 1) fields with $>2$ nodes of injury to Cry34/35Ab1 corn, 2) fields with $>1$ node of root injury to corn pyramided with Cry34/35Ab1 and either mCry3A or Cry3Bb1, 3) fields with $>0.5$ node but $<1.0$ node of injury to corn pyramided with Cry34/35Ab1 and Cry3Bb1, 4) fields with $>2$ nodes of injury to Cry3Bb1 corn, and 5) control populations. The random factor in the ANOVA was population nested within population class. When a significant effect of population class was present, pairwise comparisons were made among all classes of populations using the PDIFF statement in PROC MIXED with $P$ values adjusted based on a Bonferroni correction. Data on the proportion of larvae in each of the three instars (i.e., first, second, and third) were analyzed separately by instar and hybrid using the same approach applied to analyze proportion mortality.

For each population on each type of Bt corn, corrected proportional survival was calculated as 1 -corrected proportional mortality based on the correction of Abbott (1925), which was [(proportion survival on non-Bt near isoline-proportion survival on Bt corn $) \div$ proportion survival on non-Bt near isoline]. Values for corrected survival per population were then used to calculate mean corrected survival for each class of populations: 1) fields with $>2$ nodes of injury to Cry34/35Ab1 corn, 2) fields with $>1$ node of root injury to corn pyramided with Cry34/ $35 \mathrm{Ab} 1$ and either mCry3A or Cry3Bb1, 3) fields with $>0.5$ node but $<1.0$ node of injury to corn pyramided with Cry34/35Ab1 and Cry3Bb1, 4) fields with $>2$ nodes of injury to Cry3Bb1 corn, and 5) control populations. A value of 1 for corrected survival would indicate equal survival between $\mathrm{Bt}$ and non-Bt corn (i.e., complete resistance). As such, a one-tailed t-test was conducted to test whether corrected survival of each class of populations on each type of $\mathrm{Bt}$ corn was significantly less than one (PROC TTEST). The null hypothesis was that a specific class of populations (e.g., populations from fields with $>2$ nodes of injury to Cry3Bb1 corn) was completely resistant to a specific type of $\mathrm{Bt}$ corn (e.g., Cry3Bb1 corn), and the alternative hypothesis was that a specific class of populations showed incomplete resistance to a specific type of Bt corn. Additionally, for each class of field populations on each type of Bt corn, a resistance ratio (RR) was calculated as corrected survival on a specific type of Bt corn divided by corrected survival for control populations on the same type of Bt corn.

\section{Results}

No significant differences were detected among classes of populations for survival on non-Bt corn, and this was the case for the non$\mathrm{Bt}$ near isoline to Cry34/35Ab1 corn, the non-Bt near isoline to Cry3Bb1 corn, and the non-Bt near isoline to mCry3A corn (Fig. 2; Table 2). This indicates that all population classes had similar larval viability in the absence of $\mathrm{Bt}$ toxin. By contrast, significant differences among populations were detected for survival on all types of Bt corn tested, which included Cry34/35Ab1 corn, Cry3Bb1 corn, and mCry3A corn (Fig. 2; Table 2).

Compared with control populations, survival on Cry34/35Ab1 corn was significantly greater for western corn rootworm from fields where Cry34/35Ab1 corn suffered $>2$ nodes of root injury $(\mathrm{RR}=5.85)$ and fields where corn pyramided with Cry34/35Ab1 and either Cry3Bb1 or mCry3A suffered $>1$ node of root injury $(\mathrm{RR}=6.16)$, which indicates the presence of resistance to Cry34/ $35 \mathrm{Ab} 1$ corn in these field populations (Fig. 2A; Table 3). By contrast, no significant difference in survival on Cry34/35Ab1 corn was detected between control populations and populations from fields with $>2$ nodes of injury to Cry3Bb1 corn $(R R=1.66)$ or fields with $>0.5$ nodes but $<1.0$ node of injury to corn pyramided with Cry34/ $35 \mathrm{Ab} 1$ and Cry3Bb1 (RR=1.53; Fig. 2A; Table 3). In all cases, corrected survival on Cry34/35Ab1 corn was significantly less than one, indicating that resistance, when present, was incomplete (Table 3).

For survival on Cry3Bb1 corn, all classes of field populations had significantly greater survival on Cry3Bb1 corn than was observed for control populations (Fig. 2B). Resistance ratios among these classes of field populations ranged from 15.2 to 21.9 , and in all cases, corrected survival on Cry3Bb1 corn did not differ from 1 (Table 3), indicating complete resistance to Cry3Bb1 corn for each class of field populations.

Results were similar for survival on mCry3A corn. With the exception of fields where $>0.5$ nodes but $<1.0$ node of injury was observed for corn pyramided with Cry34/35Ab1 and Cry3Bb1 $(\mathrm{RR}=2.33)$, all other classes of field populations had significantly greater survival on mCry $3 \mathrm{~A}$ corn than was observed for control populations, and resistance ratios ranged from 4.59 to 6.48 (Fig. 2C; Table 3). This indicates resistance to mCry3A corn for fields with $>2$ nodes of injury to Cry34/35Ab1 corn, fields with $>1$ node of root injury to corn pyramided with Cry34/35Ab1 and either mCry3A or Cry3Bb1, and fields with $>2$ nodes of injury to Cry3Bb1 corn. Corrected survival on mCry3A corn did not differ from 1 for populations from fields with $>2$ nodes of injury to Cry34/35Ab1 corn and from fields with $>1$ node of root injury to corn pyramided with Cry34/35Ab1 and either mCry3A or Cry3Bb1, indicating complete resistance to mCry $3 \mathrm{~A}$ in those classes of field populations (Table 3). However, for populations from fields with $>2$ nodes of injury to Cry3Bb1 corn, resistance to mCry3A was incomplete (Table 3).

In general, few differences were found among classes of populations for larval developmental rate, which was measured as the proportion of larvae in each of the three instars. For non-Bt corn, only the non-Bt near isoline to Cry3Bb1 corn was associated with differences in developmental rate (Table 4). While a significant effect of population type was present for both the proportion of second- and third-instar larvae on the non-Bt near isoline to Cry3Bb1 corn, no significant pairwise differences were detected (Table 4). For Bt corn, 

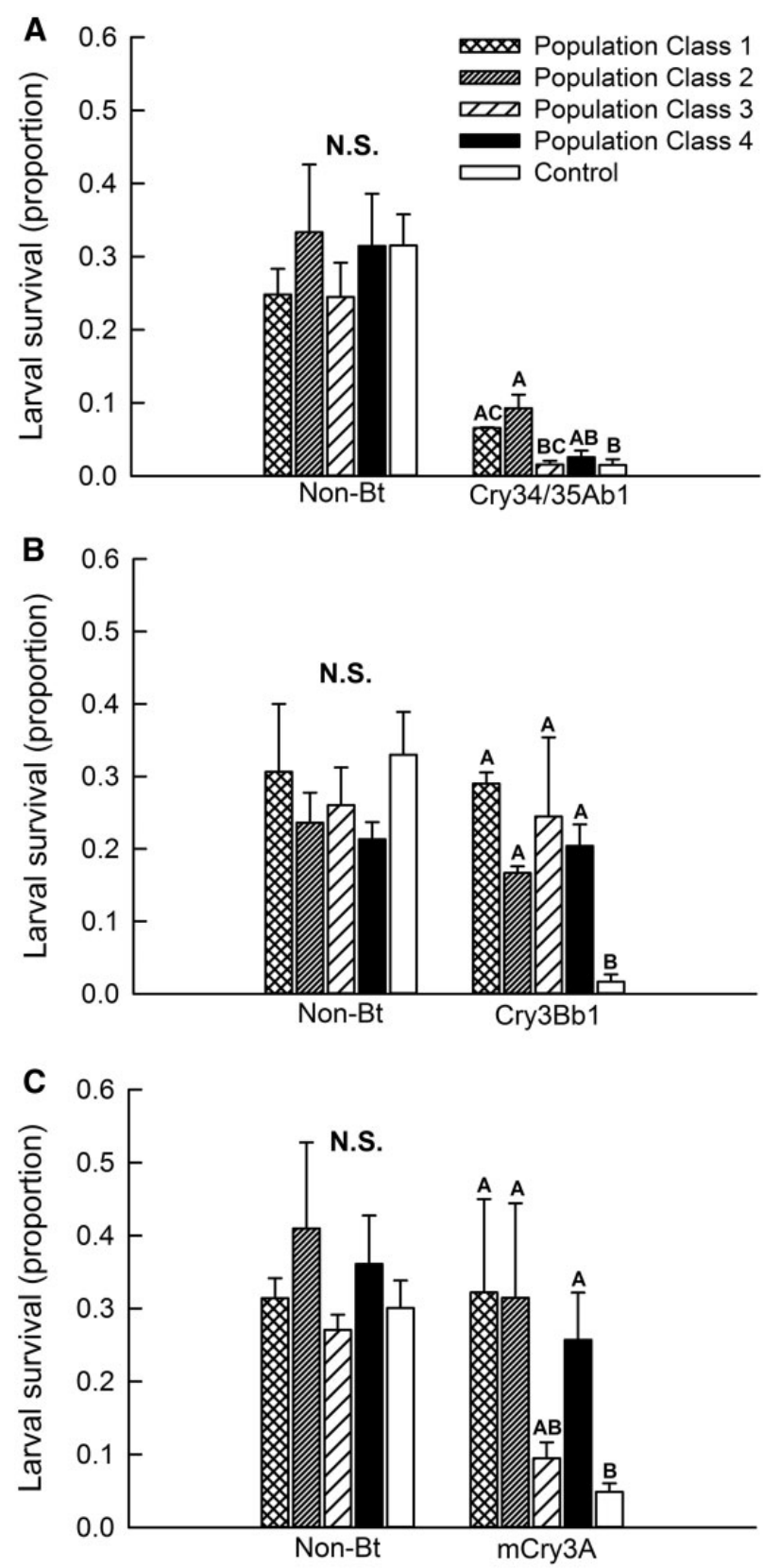

Fig. 2. Survival of western corn rootworm larvae on (A) Cry34/35Ab1 corn, (B) Cry3Bb1 corn, and (C) mCry3A corn. In each panel, non-Bt corn represents the non-Bt near isoline of the Bt hybrid. Population classes are: 1) fields with $>2$ nodes of injury to Cry34/35Ab1 corn, 2) fields with $>1$ node of root injury to corn pyramided with Cry34/35Ab1 and either mCry3A or Cry3Bb1, 3) fields with $>0.5$ node but $<1.0$ node of injury to corn pyramided with Cry34/35Ab1 and Cry3Bb1, and 4) fields with $>2$ nodes of injury to Cry3Bb1 corn. Bar heights are sample means and error bars are the standard error of the mean. Letter indicate significant differences between classes of populations within each hybrid (e.g., Cry3Bb1 corn) and NS indicates that no significant difference among classes was detected with analysis of variance (see Table 2).

differences in larval developmental rate were only detected on mCry3A corn (Table 5). Significantly fewer third-instar larvae were found for control populations on mCry3A corn compared with field populations associated with $>1$ node of root injury to corn pyramided with Cry34/35Ab1 and either mCry3A or Cry3Bb1.
Table 2. Analysis of variance for larval survival in plant-based bioassays among classes of populations

\begin{tabular}{lcrr}
\hline Type of corn tested in bioassays & df & \multicolumn{1}{c}{$F$} & \multicolumn{1}{c}{$P$} \\
\hline Cry34/35Ab1 corn $^{a}$ & 4,10 & 7.98 & 0.004 \\
Non-Bt (near isoline to Cry34/35Ab1) $^{b}$ & 4,10 & 0.33 & 0.854 \\
Cry3Bb1 corn $^{c}$ & 4,10 & 22.50 & $<0.001$ \\
Non-Bt (near isoline to Cry3Bb1) $^{d}$ & 4,10 & 0.60 & 0.670 \\
mCry3A $^{e}$ & 4,10 & 7.20 & 0.005 \\
Non-Bt (near isoline to mCry3A) $^{f}$ & 4,10 & 0.66 & 0.631
\end{tabular}

The five population classes evaluated in each analysis of variance were: 1) fields with $>2$ nodes of injury to Cry34/35Ab1 corn, 2) fields with $>1$ node of root injury to corn pyramided with Cry34/35Ab1 and either mCry3A or Cry3Bb1, 3) fields with $>0.5$ node but $<1.0$ node of injury to corn pyramided with Cry34/35Ab1 and Cry3Bb1, 4) fields with $>2$ nodes of injury to Cry3Bb1 corn, and 5) control populations.

${ }^{a}$ Random factor in the model was Population(Population Type): $\chi^{2}=2.0$; $\mathrm{df}=1 ; P=0.08$.

${ }^{b}$ Random factor in the model was Population(Population Type): $\chi^{2}=2.7$; $\mathrm{df}=1 ; P=0.05$.

${ }^{c}$ Random factor in the model was Population(Population Type): $\chi^{2}=0.2$; $\mathrm{df}=1 ; P=0.33$.

${ }^{d}$ Random factor in the model was Population(Population Type): $\chi^{2}=4.5$; $\mathrm{df}=1 ; P=0.02$.

${ }^{e}$ Random factor in the model was Population(Population Type): $\chi^{2}=13.4$; $\mathrm{df}=1 ; P<0.001$.

${ }^{f}$ Random factor in the model was Population(Population Type): $\chi^{2}=3.5$; $\mathrm{df}=1 ; P=0.03$.

Table 3. Corrected survival, standard error for corrected survival, and resistance ratio among classes of populations

\begin{tabular}{lccc}
\hline Population class $^{a}$ & Cry34/35Ab1 & Cry3Bb1 & mCry3A \\
\hline 1 & $0.270^{*}$ & 1.06 & 0.997 \\
& $(0.035)$ & $(0.374)$ & $(0.320)$ \\
& 5.85 & 21.9 & 6.48 \\
2 & $0.284^{*}$ & 0.736 & 0.739 \\
& $(0.023)$ & $(0.169)$ & $(0.104)$ \\
& 6.16 & 15.2 & 4.80 \\
3 & $0.0705^{*}$ & 0.892 & $0.358^{*}$ \\
& $(0.035)$ & $(0.242)$ & $(0.108)$ \\
& 1.53 & 18.4 & 2.33 \\
4 & $0.0767^{*}$ & 1.00 & $0.706^{*}$ \\
& $(0.012)$ & $(0.218)$ & $(0.079)$ \\
& 1.66 & 20.6 & 4.59 \\
5 & $0.0461^{*}$ & $0.0485^{*}$ & $0.154^{*}$ \\
& $(0.021)$ & $(0.029)$ & $(0.029)$ \\
& & &
\end{tabular}

Data from each combination of population class by type as Bt corn are presented, from top to bottom, as corrected survival, followed by standard error for corrected survival in parentheses, followed by resistance ratio, when applicable, at the bottom.

${ }^{a}$ Classes of populations were: 1) fields with $>2$ nodes of injury to Cry34/ $35 \mathrm{Ab} 1$ corn, 2) fields with $>1$ node of root injury to corn pyramided with Cry34/35Ab1 and either mCry3A or Cry3Bb1, 3) fields with $>0.5$ node but $<1.0$ node of injury to corn pyramided with Cry34/35Ab1 and Cry3Bb1, 4) fields with $>2$ nodes of injury to Cry3Bb1 corn, and 5) control populations.

"Corrected survival was significantly less than $1.0(P \leq 0.05)$ based on a one-tailed t-test. A lack of a significant difference indicates complete resistance to a specific type of Bt corn by a specific class of populations.

\section{Discussion}

In this study, we found incomplete resistance to Cry34/35Ab1 corn by western corn rootworm populations from fields in Iowa with severe feeding injury to Cry34/35Ab1 corn ( $>2$ nodes of injury) and 
Table 4. Mean percentage in each larval instar on non-Bt hybrids and associated standard errors

\begin{tabular}{|c|c|c|c|c|c|c|c|c|c|}
\hline \multirow[t]{2}{*}{ Population class $^{a}$} & \multicolumn{3}{|c|}{ Non-Bt near isoline of Cry34/35Ab1 corn } & \multicolumn{3}{|c|}{ Non-Bt near isoline of Cry3Bb1 corn } & \multicolumn{3}{|c|}{ Non-Bt near isoline of mCry3A corn } \\
\hline & $1 \mathrm{st}$ & 2nd & $3 \mathrm{rd}$ & $1 \mathrm{st}$ & 2nd & $3 \mathrm{rd}$ & $1 \mathrm{st}$ & 2nd & $3 \mathrm{rd}$ \\
\hline 1 & $00(00)$ & $35(08)$ & $65(08)$ & $00(00)$ & $29^{\mathrm{A}}(05)$ & $71^{\mathrm{A}}(05)$ & $00(00)$ & $26(03)$ & $74(26)$ \\
\hline 2 & $00(00)$ & $24(06)$ & $76(06)$ & $01(01)$ & $19^{\mathrm{A}}(02)$ & $79^{\mathrm{A}}(03)$ & $00(00)$ & $21(01)$ & $79(01)$ \\
\hline 3 & $00(00)$ & $46(00)$ & $54(00)$ & $00(00)$ & $53^{\mathrm{A}}(10)$ & $47^{\mathrm{A}}(10)$ & $00(00)$ & $45(09)$ & $55(09)$ \\
\hline 4 & $02(01)$ & $48(03)$ & $50(03)$ & $00(00)$ & $59^{\mathrm{A}}(08)$ & $41^{\mathrm{A}}(08)$ & $02(02)$ & $46(05)$ & $53(06)$ \\
\hline 5 & $00(00)$ & $33(04)$ & $66(04)$ & $00(00)$ & $45^{\mathrm{A}}(04)$ & $55^{\mathrm{A}}(04)$ & $03(01)$ & $35(03)$ & $62(03)$ \\
\hline
\end{tabular}

Data are presented as mean followed by standard error in parentheses.

${ }^{a}$ Classes of populations were: 1) fields with $>2$ nodes of injury to Cry34/35Ab1 corn, 2) fields with $>1$ node of root injury to corn pyramided with Cry34/ $35 \mathrm{Ab} 1$ and either mCry3A or Cry3Bb1, 3) fields with $>0.5$ node but $<1.0$ node of injury to corn pyramided with Cry34/35Ab1 and Cry3Bb1, 4) fields with $>2$ nodes of injury to Cry3Bb1 corn, and 5) control populations.

*Significant differences among population classes were present based on one-way analysis of variance and letters indicate pairwise differences between means.

Table 5. Mean percentage in each larval instar on Bt hybrid and associated standard errors

\begin{tabular}{|c|c|c|c|c|c|c|c|c|c|}
\hline \multirow[t]{2}{*}{ Population class $^{a}$} & \multicolumn{3}{|c|}{ Cry34/35Ab1 corn } & \multicolumn{3}{|c|}{ Cry3Bb1 corn } & \multicolumn{3}{|c|}{ mCry3A corn } \\
\hline & $1 \mathrm{st}$ & 2nd & $3 \mathrm{rd}$ & $1 \mathrm{st}$ & 2nd & $3 \mathrm{rd}$ & $1 \mathrm{st}$ & 2nd & $3 r d^{*}$ \\
\hline 1 & $00(00)$ & $65(22)$ & $35(22)$ & $03(01)$ & $43(04)$ & $54(05)$ & $00(00)$ & $40(03)$ & $60^{\mathrm{AB}}(03)$ \\
\hline 2 & $00(00)$ & $84(04)$ & $16(04)$ & $00(00)$ & $42(15)$ & $58(15)$ & $00(00)$ & $33(01)$ & $67^{\mathrm{B}}(01)$ \\
\hline 3 & $00(00)$ & $50(50)$ & $50(50)$ & $00(00)$ & 45 (14) & $55(14)$ & $08(08)$ & $56(02)$ & $36^{\mathrm{AB}}(11)$ \\
\hline 4 & $08(08)$ & $92(08)$ & $00(00)$ & $05(05)$ & $42(05)$ & $53(10)$ & $01(01)$ & $42(09)$ & $57^{\mathrm{AB}}(10)$ \\
\hline 5 & $25(25)$ & $75(25)$ & $00(00)$ & $00(00)$ & $80(20)$ & $20(20)$ & $02(02)$ & $69(08)$ & $29^{\mathrm{A}}(08)$ \\
\hline
\end{tabular}

Data are presented as means followed by standard errors in parentheses.

${ }^{a}$ Classes of populations were: 1 ) fields with $>2$ nodes of injury to Cry34/35Ab1 corn, 2) fields with $>1$ node of root injury to corn pyramided with Cry34/ $35 \mathrm{Ab} 1$ and either mCry3A or Cry3Bb1, 3) fields with $>0.5$ node but $<1.0$ node of injury to corn pyramided with Cry34/35Ab1 and Cry3Bb1, 4) fields with $>2$ nodes of injury to Cry3Bb1 corn, and 5) control populations.

*Significant differences among population classes were present based on one-way analysis of variance and letters indicate pairwise differences between means.

corn pyramided with Cry34/35Ab1 and either Cry3Bb1 or mCry3A ( $>1$ node of injury). These populations also showed complete resistance to both Cry3Bb1 corn and mCry3A corn. Fields sampled for this study were visited in 2013, and past work has identified field populations of western corn rootworm in Iowa during 2009, 2010, and 2011 with resistance to Cry3Bb1 corn and mCry3A corn, however, not to Cry34/35Ab1 corn (Gassmann et al. 2011, 2012, 2014). As such, this work represents the first detection of field-evolved resistance to Cry34/35Ab1 corn by western corn rootworm in Iowa.

It is possible for substantial variation in root injury to exist among hybrids that contain the same Bt event targeting western corn rootworm (Gray et al. 2007). It may be the case that the particular hybrid varieties in the fields visited as part of this study produced lower levels of Bt protein than might occur for other hybrids, and that this decreased production of Bt toxin contributed to the level of injury observed in the field. Nonetheless, these high levels of feeding injury to Cry34/35Ab1 corn in the field were associated with increased survival on Cry34/35Ab1 corn in laboratory bioassays, indicating that severe injury to Cry34/35Ab1 corn in the field was associated with resistance to Cry34/35Ab1 corn. In addition to variation in the level of root injury observed in the field, level of survival for western corn rootworm can vary. For example, on Cry34/ $35 \mathrm{Ab} 1$ corn, larval survival in the field can range from $<1 \%$ to ca. 20\% (Storer et al. 2006, Petzold-Maxwell et al. 2013a). These levels of survival are consistent with a $\mathrm{Bt}$ crop that does not produce a high dose of toxin against a target pest, as is the case for Bt corn targeting western corn rootworm (Gassmann 2012, Andow et al. 2016). In cases where a baseline survival of $20 \%$ is present for a susceptible population, adding three- to sixfold resistance on top of this $20 \%$ survival may result in similar survival between $\mathrm{Bt}$ and non-Bt corn and high levels of feeding injury to Bt corn, as has been observed in the field when Cry3Bb1 resistance was present (Gassmann 2012).

Past work has found an absence of cross-resistance between Cry3Bb1 and Cry34/35Ab1 (Gassmann et al. 2011, 2012, 2014), and between mCry3A and Cry34/35Ab1 (Gassmann et al. 2014). Additionally, the mode of action likely differs between Cry34/ 35Ab1, a binary toxin, and either Cry3Bb1 or mCry3A, which are three domain toxins ( $\mathrm{Li}$ et al. 2013). The lack of cross-resistance found between these Cry3 toxins and Cry34/35Ab1 in previous work, coupled with the structural differences between these Bt toxins, suggests that the mechanism of resistance to Cry34/35Ab1 may differ from the mechanism of resistance to Cry3 toxins.

Past research with the single-plant bioassay used in this study has focused on resistance to Cry3Bb1 corn, and has found that resistance ratios of 3 to 6 are associated with severe feeding injury to Cry3Bb1 corn in the field (Gassmann et al. 2011, 2014; Andow et al. 2016). Across multiple years and multiple states, severe injury to Cry3Bb1 corn has been associated with increased survival in plant-based bioassays (Gassmann et al. 2011, 2012, 2014; Wangila et al. 2015; Schrader et al. 2016). On-farm studies in fields where Cry3Bb1 resistance has been detected with plant-based bioassays have found elevated injury to Cry3Bb1 corn and elevated survival by western corn rootworm compared to known susceptible controls or compared to Cry34/35Ab1 corn (Gassmann 2012, Shrestha et al. 2016). Additionally, US EPA recommends the use of plant-based bioassays for monitoring of Bt resistance by western corn rootworm (EPA 2013, 2016a). Taken together these data suggest that increased survival on Cry34/35Ab1 corn in this study, observed for populations sampled from fields where Cry34/35Ab1 corn suffered 
high levels of feeding injury, is indicative of the development of resistance to Cry34/35Ab1 by these populations (Fig 2A; Table 3). However, lower survival on Cry34/35Ab1 corn, compared to nonBt corn, indicates that this resistance is incomplete.

When resistance to Cry3Bb1 corn was first detected in 2009, all fields where resistance was found were characterized by a history of continuous corn cultivation (i.e., $\geq 7 \mathrm{yr}$ ) and continuous use of Cry3Bb1 corn for 3-7 yr. In this study, resistance to Cry34/35Ab1 corn followed a similar pattern in some cases but not others. Fields with $>1$ node of injury to pyramided corn had been in continuous corn cultivation for $7-10 \mathrm{yr}$, and there was a history of cultivation of Bt corn, although the intensity of use for either Cry34/35Ab1 or Cry3Bb1 was only 1-2 yr in each field (Table 1 ). By contrast fields with $>2$ nodes of injury to Cry34/35Ab1 corn had only been planted to corn for 2-3 yr and did not have a history of Cry34/35Ab1 corn (Table 1). This suggests that the resistance to Cry34/35Ab1 observed in fields with $>2$ nodes of injury to Cry34/35Ab1 corn arose through selection in other fields with subsequent dispersal of rootworm into fields where injury was observed. To date, routine monitoring of western corn rootworm populations has not detected resistance to Cry34/35Ab1, suggesting that investigations of field failures may be more useful for early detection of resistance (Andow et al. 2016).

Cry3Bb1 corn for management of western corn rootworm was registered in 2003, and Cry34/35Ab1 corn was registered in 2005 (EPA 2005, 2010). Initially, in 2009, field populations with resistance to Cry3Bb1 corn displayed incomplete resistance (i.e., lower survival on $\mathrm{Bt}$ corn compared to non-Bt corn), but over time the level of resistance increased and complete resistance was present for field populations studied in both 2010 and 2011 (Gassmann et al. 2011, 2012, 2014). Similarly, incomplete resistance to Cry34/ $35 \mathrm{Ab} 1$ corn was found among the populations tested in this study. The rate at which resistance to Cry34/35Ab1 corn may increase in the field will be due in part to the intensity of selection for resistance in subsequent years. The recent pyramiding of Cry34/35Ab1 with either mCry3A or Cry3Bb1, and the continued cultivation of corn producing Cry34/35Ab1 singly, may result in a greater proportion of the landscape being planted to corn containing Cry34/35Ab1 than occurred in previous years. As a result, the level of resistance observed among field populations may increase over time, as was observed for resistance to Cry3Bb1 corn (Gassmann et al. 2014).

Adaptation of western corn rootworm to Bt corn in the field was likely facilitated by the lack of a high dose produced by all commercialized Bt corn targeting western corn rootworm (Gassmann 2012, Andow et al. 2016). High-dose Bt crops delay resistance by killing heterozygous resistant individuals, which in turn results in functionally recessive resistance (Tabashnik et al. 2008, Carrière et al. 2010). Bt crops that produce less than a high dose of toxin permit some survival of heterozygous individuals, which can increase the rate of resistance evolution compared to high-dose events (Tabashnik et al. 2008, Tabashnik and Gould 2012). Additionally, low rates of dispersal by adult western corn rootworm prior to mating likely limited mixing between refuge individuals and Bt-selected individuals, especially when structured refuges (i.e., block refuges) were planted, which also will facilitate resistance to Bt corn (Spencer et al. 2009, Gassmann 2012, Hughson and Spencer 2015, Andow et al. 2016). Furthermore, high rates of adoption of Bt corn by farmers and a lack of compliance in planting of non-Bt refuges may further hasten resistance development (Jaffe 2009, James 2013). Recent adoption of integrated refuges (i.e., seed blends) may help to increase both compliance with refuge planting and spatial proximity of refuge plants to Bt plants (EPA 2011b, 2012).
However, these factors will not decrease the intensity of selection for resistance. By contrast, using Bt corn more judiciously as part of a broader integrated pest management (IPM) approach should decrease the intensity of selection for resistance.

In general, our hypotheses about the association between injury in the field and resistance were supported, but with a few exceptions. In the case of pyramided corn with $>0.5$ nodes but $<1.0$ nodes of root injury, resistance to Cry3Bb1 corn was present but resistance to Cry34/35Ab1 corn was not detected. This suggests that the feeding injury observed in the field arose because of resistance to one of the two toxins in the pyramid. Additionally, a co-occurrence of resistance to Cry3Bb1 and mCry3A corn was not found in all cases. Past work has found cross-resistance to $\mathrm{mCry} 3 \mathrm{~A}$ and Cry3Bb1 (Gassmann et al. 2014, Wangila et al. 2015), and that led to the hypothesis that resistance to either Cry3Bb1 or mCry3A should be accompanied by resistance to the other toxin. In general, for three out of four classes of field populations, this was the case, with significantly greater survival on both Cry3Bb1 corn and mCry3A corn observed among field populations compared to experimental controls. However, one class of field populations (pyramided corn with $>0.5$ nodes but $<1.0$ nodes of root injury) displayed significantly greater survival than control populations on Cry3Bb1 corn but not on mCry3A corn (Fig. 2), and for populations sampled from fields with $>2$ nodes of injury to Cry3Bb1 corn, resistance to $\mathrm{Cry} 3 \mathrm{Bb} 1$ was complete but resistance to mCry3A was incomplete (Table 3). Among field populations, seven of nine had been exposed to Cry3Bb1 corn in the field from which they were collected but only two of nine populations were exposed to mCry3A, implying that resistance to both Cry3Bb1 and mCry3A corn arose primarily from exposure to Cry3Bb1 corn (Table 1). These results suggest that there may be multiple mechanisms of resistance to Cry3Bb1 corn and only some of those mechanisms confer resistance to $\mathrm{mCry} 3 \mathrm{~A}$ corn.

For single-plant bioassays with western corn rootworm, data on larval survival are informative for detecting resistance, but data on larval development are not consistently associated with the presence or absence of resistance. For example, Gassmann et al. (2014) found no difference in the proportion of larvae in the various instars between resistant and susceptible populations, although significant differences in survival were present. In the present study, larval developmental rate on Bt corn only differed among populations on mCry3A corn, and was positively associated with resistance only for populations from fields with $>1$ node of root injury to pyramided corn (Table 5). By contrast, no differences in larval development were observed among classes of populations for either Cry34/35 Ab1 corn or Cry3Bb1 corn (Table 5). Additionally, in past studies, resistance to mCry3A corn did not significantly affect larval development rate in single-plant bioassays with mCry3A corn (Gassmann et al. 2014). While developmental rate may not be a reliable indicator of resistance with single-plant bioassays, it may be an informative metric in other bioassay approaches such as bioassays with seedling mats (Lefko et al. 2008, Nowatzki et al. 2008, Deitloff et al. 2015).

The bioassay data reported here show the first cases of resistance to Cry34/35Ab1 corn by western corn rootworm. While resistance was incomplete, it was associated with severe feeding injury to Cry34/45Ab1 corn. Using IPM approaches such as crop rotation may help to mitigate the injury to Cry34/35Ab1 corn that is associated with resistance by reducing the abundance of western corn rootworm in fields. Additionally, more diversified management plans will help to reduce selection for resistance. Because of resistance to Cry3Bb1 and mCry3A corn by western corn rootworm, preserving susceptibility of rootworm populations to Cry34/35Ab1 
corn is important for management of this pest. Recent pyramiding of Cry34/35Ab1 corn with either Cry3Bb1 or mCry3A likely will increase selective pressure on pest populations for resistance to Cry34/ $35 \mathrm{Ab} 1$, especially in cases where western corn rootworm populations are resistant to Cry3Bb1 and mCry3A. Judicious use of Cry34/ $35 \mathrm{Ab} 1$ corn, in a broader IPM context, will likely be essential for preserving the utility of this pest management tool.

\section{Acknowledgments}

We thank Dow AgroSciences, Monsanto, and Syngenta for providing the corn seed used to conduct plant-based bioassays, and Chad Nielson, Deb Patterson, and several students for technical assistance with control populations. Mention of trade names or commercial products in this publication is solely for the purpose of providing specific information and does not imply recommendation or endorsement by the U.S. Department of Agriculture. USDA is an equal opportunity provider and employer. This research was supported by Biotechnology Risk Assessment Grant Program competitive grant 2012-33522-20010 from the USDA National Institute of Food and Agriculture.

\section{References}

Abbott, W. S. 1925. A method of computing the effectiveness of an insecticide. J. Econ. Entomol. 18: 265-267.

Abendroth, L. J., R. W. Elmore, M. J. Boyer, and S. K. Marlay. 2011. Corn growth and development. vol. PMR 1009, Iowa State University, Ames, Iowa.

Andow, D. A., S. G. Pueppke, A. W. Schaafsma, A. J. Gassmann, T. W. Sappington, L. J. Meinke, P. D. Mitchell, T. M. Hurley, R. L. Hellmich, and R. P. Porter. 2016. Early detection and mitigation of resistance to Bt maize by western corn rootworm (Coleoptera: Chrysomelidae) J. Econ. Entomol. 109: 1-12.

Carrière, Y., D. W. Crowder, and B. E. Tabashnik. 2010. Evolutionary ecology of insect adaptation to Bt crops. Evol. Appl. 3: 561-573.

Cullen, E. M., M. E. Gray, A. J. Gassmann, and B. E. Hibbard. 2013. Resistance to $\mathrm{Bt}$ corn by western corn rootworm (Coleoptera: Chrysomelidae) in the U.S. Corn Belt. J. Integr. Pest Manag. 4(3): IPM13012 (doi: dx.doi.org/10.1603/IPM13012)

Deitloff, J., M. W. Dunbar, D. A. Ingber, B. E. Hibbard, and A. J. Gassmann. 2015. Effects of refuges on the evolution of resistance to transgenic corn by the western corn rootworm, Diabrotica virgifera virgifera LeConte. Pest Manag. Sci. 72: 190-198. (DOI 10.1002/ps.3988).

Dun, Z., P. D. Mitchell, and M. Agosti. 2010. Estimating Diabrotica virgifera virgifera damage functions with field trial data: Applying an unbalanced nested error component model. J. Appl. Entomol. 134: 409-419.

(EPA) Environmental Protection Agency. 2005. Biopesticides Registration Action Document: Bacillus thuringiensis Cry34Ab1 and Cry35Ab1 Proteins and the Genetic Material Necessary for Their Production (PHP17662 T-DNA) in Event DAS-59122-7 Corn (OECD Unique Identifier: DAS-59122-7). (http://www3.epa.gov/pesticides/chem_search/ reg_actions/pip/cry3435ab1-brad.pdf) (accessed 4 January 2016).

(EPA) Environmental Protection Agency. 2006. Biopesticides registration action document: Modified Cry3A Protein and the Genetic Material Necessary for its Production (Via Elements of pZM26) in Event MIR604 Corn SYN-IR604-8 (http://www.epa.gov/oppbppd1/biopesticides/pips/ mcry3a-brad.pdf) (accessed 4 January 2016).

(EPA) Environmental Protection Agency. 2009. Pesticide Fact Sheet. (http:// www3.epa.gov/pesticides/chem_search/reg_actions/pip/smartstax-fact sheet.pdf) (accessed 4 January 2016).

(EPA) Environmental Protection Agency. 2010. Biopesticides registration action document: Bacillus thuringiensis Cry3Bb1 Protein and the Genetic Material Necessary for Its Production (Vector PV-ZMIR13L) in MON 863 Corn (OECD Unique Identifier: MON-ØØ863-5). (http://www3.epa.gov/ pesticides/chem_search/reg_actions/pip/cry3bb1-brad.pdf) (accessed 4 January 2016).
(EPA) Environmental Protection Agency. 2011a. Bt11 x 59122-7 x MIR 604 x 1507 (Cry1Ab x Cry34/35 x mCry3A x Cry1F). (http://www.epa.gov/ingre dients-used-pesticide-products/current-previously-registered-section-3plant-incorporated) (accessed 4 January 2016).

(EPA) Environmental Protection Agency. 2011b. Biopesticides Registration Action Document: MON 89034 x TC1507 x MON 88017 x DAS-59122-7 $\left(\operatorname{SmartStax}^{(\otimes)}\right)$ B.t. Corn Seed Blend. (http://www3.epa.gov/pesticides/chem search/reg_actions/pip/smartstax-seedblend.pdf) (accessed 4 January 2016).

(EPA) Environmental Protection Agency. 2012. Optimum AcreMax Xtreme (Cry1F x Cry34/35 x Cry1Ab x mCry3A) - seed blend. (http://www.epa. gov/ingredients-used-pesticide-products/current-previously-registered-sec tion-3-plant-incorporated) (accessed 4 January 2016).

(EPA) Environmental Protection Agency. 2013. White Paper on Corn Rootworm Resistance Monitoring for Bt Plant-Incorporated Protectants. (http://www.regulations.gov/\#!documentDetail;D=EPA-HQ-OPP-20130490-0008) (accessed 15 April 2016).

(EPA) Environmental Protection Agency. 2016a. Framework to delay corn rootworm resistance (https://www.epa.gov/regulation-biotechnologyunder-tsca-and-fifra/framework-delay-corn-rootworm-resistance) (accessed 6 April 2016).

(EPA) Environmental Protection Agency. 2016b. Current and Previously Registered Section 3 Plant-Incorporated Protectant (PIP) Registrations. (http://www.epa.gov/ingredients-used-pesticide-products/current-previ ously-registered-section-3-plant-incorporated) (accessed 4 January 2016).

Gassmann, A. J. 2012. Field-evolved resistance to Bt maize by western corn rootworm: predictions from the laboratory and effects in the field. J. Invertebr. Pathol. 110: 287-293.

Gassmann, A. J., J. L. Petzold-Maxwell, R. S. Keweshan, and M. W. Dunbar. 2011. Field-evolved resistance to Bt maize by western corn rootworm. PLoS ONE 6: e22629. (doi:22610.21371/journal.pone.0022629).

Gassmann, A. J., J. L. Petzold-Maxwell, R. S. Keweshan, and M. W. Dunbar. 2012. Western corn rootworm and Bt maize: Challenges of pest resistance in the field. GM Crops Food 3: 235-244.

Gassmann, A. J., J. L. Petzold-Maxwell, E. H. Clifton, M. W. Dunbar, A. M. Hoffmann, D. A. Ingber, and R. S. Keweshan. 2014. Field-evolved resistance by western corn rootworm to multiple Bacillus thuringiensis toxins in transgenic maize. Proc. Natl. Acad. Sci. USA. 111: 5141-5146.

Gould, F. 1998. Sustainability of transgenic insecticidal cultivars: Integrating pest genetics and ecology. Annu. Rev. Entomol. 43: 701-726.

Gray, M. E., K. L. Steffey, R. E. Estes, and J. B. Schroeder. 2007. Responses of transgenic maize hybrids to variant western corn rootworm larval injury. J. Appl. Entomol. 131: 386-390.

Gray, M. E., T. W. Sappington, N. J. Miller, J. Moeser, and M. O. Bohn. 2009. Adaptation and invasiveness of western corn rootworm: intensifying research on a worsening pest. Annu. Rev. Entomol. 54: 303-321.

Hammack, L., M. M. Ellsbury, R. L. Roehrdanz, and J. L. J. Pikul. 2003. Larval sampling and instar determination in field populations of northern and western corn rootworm (Coleoptera: Chrysomelidae). J. Econ. Entomol. 96: 1153-1159.

Hughson, S. A., and J. L. Spencer. 2015. Emergence and abundance of western corn rootworm (Coleoptera: Chrysomelidae) in Bt cornfields with structured and seed blend refuges. J. Econ. Entomol. 108: 114-125.

Jaffe, G. 2009. Complacency on the Farm: Significant Noncompliance with EPA's Refuge Requirements Threatens the Future Effectiveness of Genetically Engineered Pest-protected Corn. Center for Science in the Public Interest, Washington, DC.

James, C. 2013. Global Status of Commercialized Biotech/GM Crops: 2013. ISAAA Brief No. 46. ISAAA, Ithaca, New York.

Keweshan, R. S., G. P. Head, and A. J. Gassmann. 2015. Effects of pyramided $\mathrm{Bt}$ corn and blended refuges on western corn rootworm and northern corn rootworm (Coleoptera: Chrysomelidae). J. Econ. Entomol. 108: 720-729.

Lefko, S. A., T. M. Nowatzki, S. D. Thompson, R. R. Binning, M. A. Pascual, M. L. Peters, E. J. Simbro, and B. H. Stanley. 2008. Characterizing laboratory colonies of western corn rootworm (Coleoptera: Chrysomelidae) selected for survival on maize containing event DAS-59122-7. J. Appl. Entomol. 132: 189-204. 
Levine, E., and H. Oloumi-Sadeghi. 1991. Management of diabroticite rootworms in corn. Annu. Rev. Entomol. 36: 229-255.

Li, H., M. Olson, G. Lin, T. Hey, S. Y. Tan, and K. E. Narva. 2013. Bacillus thuringiensis $\mathrm{Cry} 34 \mathrm{Ab} 1 / 35 \mathrm{Ab} 1$ interactions with western corn rootworm midgut membrane binding sites. PLoS ONE 8: e53079. (doi:10.1371/ journal.pone.0053079).

Meinke, L. J., B. D. Siegfried, R. J. Wright, and L. D. Chandler. 1998. Adult susceptibility of Nebraska western corn rootworm (Coleoptera: Chrysomelidae) populations to selected insecticides. J. Econ. Entomol. 91: 594-600.

Meinke, L. J., T. W. Sappington, D. W. Onstad, T. Guillemaud, N. J. Miller, J. Komáromi, N. Levay, L. Furlan, J. Kiss, and F. Toth. 2009. Western corn rootworm (Diabrotica virgifera virgifera LeConte) population dynamics. Agric. For. Entomol. 11: 29-46.

Nowatzki, T. M., S. A. Lefko, R. R. Binning, S. D. Thompson, T. A. Spencer, and B. D. Siegfried. 2008. Validation of a novel resistance monitoring technique for corn rootworm (Coleoptera: Chrysomelidae) and event DAS59122-7 maize. J. Appl. Entomol. 132: 177-188.

Oleson, J. D., Y.-L. Park, T. M. Nowatzki, and J. J. Tollefson. 2005. Node-injury scale to evaluate root injury by corn rootworms (Coleoptera: Chrysomelidae). J. Econ. Entomol. 98: 1-8.

Petzold-Maxwell, J. L., S. T. Jaronski, E. H. Clifton, M. W. Dunbar, M. A. Jackson, and A. J. Gassmann. 2013a. Interactions among Bt maize, entomopathogens and rootworm species (Coleoptera: Chrysomelidae) in the field: Effects on survival, yield and root injury. J. Econ. Entomol. 106: 622-632.

Petzold-Maxwell, J. L., L. J. Meinke, M. E. Gray, R. E. Estes, and A. J. Gassmann. 2013b. Effect of Bt maize and soil insecticides on yield, injury, and rootworm survival: Implications for resistance management. J. Econ. Entomol. 106: 1941-1951.

Roush, R. T. 1998. Two-toxin strategies for management of insecticidal transgenic crops: can pyramiding succeed where pesticide mixtures have not? Philos. Trans. R. Soc. Lond. B. Biol. Sci. 353: 1777-1786.

SAS. 2013. SAS Enterprise Guide 6.1. SAS Institute Inc, Cary.

Schrader, P. M., R. E. Estes, N. A. Tinsley, A. J. Gassmann, and M. E. Gray. 2016. Evaluation of adult emergence and larval root injury for
Cry3Bb1-resistant populations of the western corn rootworm. J. Appl. Entomol. (in press).

Shrestha, R. B., S.R.K. Jakka, B. W. French, and A. J. Gassmann. 2016. Fieldbased assessment of resistance to Bt corn by western corn rootworm (Coleoptera: Chrysomelidae). J. Econ. Entomol. (in press) (DOI: http://dx. doi.org/10.1093/jee/tow087).

Spencer, J. L., E. Levine, S. A. Isard, and T. R. Mabry. 2005. Movement, dispersal and behaviour of western corn rootworm adults in rotated maize and soybean fields, pp. 121-144. In S. Vidal, U. Kuhlmann and C. R. Edwards (eds.), Western Corn Rootworm: Ecology and Management. CABI Publishing, Cambridge, United Kingdom.

Spencer, J. L., B. E. Hibbard, J. Moeser, and D. W. Onstad. 2009. Behaviour and ecology of the western corn rootworm (Diabrotica virgifera virgifera LeConte). Agric. For. Entomol. 11: 9-27.

Spencer, J. L., S. A. Hughson, and E. Levine. 2014. Insect resistance to crop rotation, pp. 233-278. In D. W. Onstad (ed.), Insect Resistance Management: Biology, Economics and Predictions. Academic Press, London.

Storer, N. P., J. N. Babcock, and J. M. Edwards. 2006. Field measures of western corn rootworm (Coleoptera: Chrysomelidae) mortality caused by Cry34/Cry35Ab1 proteins expressed in maize event 59122 and implications for trait durability. J. Econ. Entomol. 99: 1381-1387.

Tabashnik, B. E., and F. Gould. 2012. Delaying corn rootworm resistance to Bt corn. J. Econ. Entomol. 105: 767-776.

Tabashnik, B. E., A. J. Gassmann, D. W. Crowder, and Y. Carrière. 2008. Insect resistance to Bt crops: Evidence versus theory. Nat. Biotechnol. 26: 199-202.

Tinsley, N. A., R. E. Estes, and M. E. Gray. 2013. Validation of a nested error component model to estimate damage caused by corn rootworm larvae. J. Appl. Entomol. 137: 161-169.

Wangila, D. S., A. J. Gassmann, J. L. Petzold-Maxwell, B. W. French, and L. J. Meinke. 2015. Susceptibility of Nebraska western corn rootworm populations (Coleoptera: Chrysomelidae) populations to Bt corn events. J. Econ. Entomol. 108: 742-751. 